"Das Glesichgewicht zwischen Basen und Säueren im tierschen Organismus", Ergeb. der Physiol., 8, 254). The milestone which marks that phase is the "Henderson-Hasselbalch equation", stating that the hyddrogen ion concentration of a solution containing carbonate, bicarbonate, and carbon dioxide is proportional to the ratio of the free to the combined carbonic acids. Perhaps his greatest contribution was his description of blood as a physico-chemical system. He described the red corpuscles in terms of the concentrations of eight components so connected that the alteration of any one equilibrium invoked a consequential alteration in all the others. This doctrine Henderson elaborated in his classical book "Blood"- the written record of his Silliman Lectures-in which, both for normal blood and that characteristic of certain diseases, the consequential inter-relations of the various factors involved were set forth in more than one hundred nomograms.

To such a mind as Henderson's, it was possible to treat of this great field without acquiring any mastery of the precise experimental techniques by which the data were obtained. It sufficed for him if the data which he plotted were reliable. He therefore, in collaboration with van Slyke, organized a large circle of extremely able experimenters, some in New York, some in Boston, and some farther afield, who undertook the necessary analyses.

It was not possible, however, for Henderson to treat of the physico-chemical blood picture, or rather blood kaleidoscope, without being intensely interested in the philosophical relation of environment to the change which it wrought in the blood of the organism. This interest was responsible for two books, "The Fitness of Environment", and "The Order of Nature". soThe study of environment at once locates Henderson's veneration for Claude Bernard, and the name of Claude Bernard leads to Henderson's love of France. He particularly enjoyed the tenure of exchange professorships at Paris and Grenoble. He held the Legion of Honour, and was a foreign member of the Académie de Médecine (Paris). He travelled on French ships, and enjoyed French wines and French cookery. Henderson was no mean cook himself; indeed, during the war years of 1917-18 he was a constituted American authority on the properties of gluten and the science of baking. Other books were "The Fitness of Environment, and "Pareto's Sociology",

Henderson was a wonderful friend and a wonderful host, particularly perhaps at his summer camp, at Morgan's Center in Vermont. He loved to entertain his friends, and so did his wife. Morgan's Center is in hilly country-country which had once been in cultivation, but now has relapsed to a birch wood. Here on the edge of the lake, the very edge (so that you can dive in from the verandah), was the central cottage where one ate and smoked; the premises expanded on what Henderson called the 'village system', which meant that he bought some window frames from a Chicago stores, and the local carpenter built a hut of perhaps a couple of sleeping rooms around the windows.

The nineteen-twenties were prosperous years in the United States, and the loyalty of her sons saw to it that Harvard participated in full measure. Under the wise guidance of President Lowell it was a time of great expansion on both the scholastic and social sides. In the planning of this expansion Henderson took a very important part-a part for which his wide academic outlook on one hand, and his great social gifts on the other, made him peculiarly valuable. Chairs were created, departments came into being on a basis of wide culture; among these must be mentioned the Fatigue Laboratory of the Harvard School of Business Administration, which dealt largely with muscular fatigue, in its widest sense, and the establishment of a human base-line in such matters ; this was Henderson's peculiar pied-de-terre. On the social side the expansion took the direction of an endeavour to incorporate into Harvard what was socially desirable in the older English universities while in no wise doing violence to Harvard itself. While, therefore, Harvard still remained Harvard, new houses of residence sprang up, each presided over by a Master, and named after great Harvard men of former times. Thus there was a considerable increase in the number of men-as we would say- 'in College'. But among the other new features of the Harvard constitution was one particularly precious to Henderson, one for which he was largely responsible, and one of which he was himself chairman, "The Society of Fellows"*.

This tribute would be incomplete without a refer. ence to Henderson's intense desire to knit more closely British and American science, and probably he did much more than appears in successfully accomplishing this. Yet his work was a broader one; it was to knit British and American culture, indeed to knit Britain and America themselves, not perhaps formally, but none the less really. It is significant that only illness prevented his giving the Pilgrim Lecture in London.

Lawrence Henderson received many foreign recog. nitions of his work, including an honorary Sc.D. in Cambridge. He married Edith Lawrence Thayer in 1910 and leaves one son.

A few weeks ago Sir Charles Sherrington passed a photograph of Lawrence Henderson hanging in the Laboratory. He glanced at it and said, half to himself, "A great man, that."

\section{J. BARCROHT.}

* The term 'fellow' is used in at least three senses at Harvard. (1) The charter of 1650 vested "sundry guiftes legacies landes and Revennewes in the President and Fellows". Now, the Corporation consists of the President, five fellows and a treasurer, who in the last resort act Society of Fellows, consisting of nine senior fellows, of whom the President of the University and the Deans of the Faculties of Arts and Sciences are ex-officio, while the chairman (lately Lawrence Henderson) and six fellows are elected by the Corporation and conHenderson) and six fellows are elected by the corporation and confirmed by the Board of Overseers. The senior fellows select junior
fellows and recommend them to the Corporation for appointment. "These men are selected for their promise of notable contribution to knowledge and thought. . . " A junior fellow has free board-residence in a house and an annual emolument of 1,250-1,500 dollars. (3) Numerous fellowships also exist in connexion with the faculties which are of

\section{Prof. Waiter Nernst, For. Mem. R.S.}

$T N$ the passing of Walter Nernst, Nobel laureate, physical chemistry has lost a notable leader. From 1894 he was professor at Göttingen, from 1905 in Berlin, afterwards, until 1924, director of the Reichsanstalt, and from 1925 until his retirement director of the Physical Institute in Berlin. After training as a physicist he became assistant in Ostwald's laboratory in Leipzig, where he was additional professor in $189 \mathrm{I}$, and his earlier work was concerned with the broadening and deepening of what was then the 'new' physical chemistry, which centred around the theory of electrolytic dissociation and was so enthusiastically received and developed in the Leipzig school. Ostwald turned more and more from the atomic and molecular conceptions then 
ruling in chemistry, and sought to replace them by "Energetics", or non-hypothetical laws based on the transformations of energy. Nernst always insisted, on the contrary, that thermodynamics and molecular theory must hold equal rank in a complete interpretation of physico-chemical phenomena. This is the key to nearly all his work, and is reflected in the title of his text-book : "Theoretical Chemistry from the Standpoint of Avogadro's Rule and Thermodynamics".

Of the large number of subjects which Nernst investigated, it is only possible in a brief notice to mention some in which he appears as a theorist and experimenter of great originality. These include his work on electrochemistry, the heat theorem and the quantum theory of solids.

In the electrochemical researches, three groups are most prominent. The first was the theory of the galvanic cell based on the idea of electrolytic solution pressure-the tendency of an electrode to throw out charged ions to a limit balanced by the osmotic pressure of the solution, and so to develop a potential difference. The formulæ based on this are still the foundation of the theory of electromotive force. Incidentally, his proposal to use the hydrogen electrode as the standard of electrode potential is still in use. Closely related to this work is that on the potential differences set up between solutions of electrolytes in contact. The theory of the effect of an electrolyte on the solubility of another having a common ion ('solubility product') threw light on many branches of chemical work, and the so-called distribution law, giving the way in which a substance distributes itself between two non-miscible solvents, is one of the most important in the study of heterogeneous equilibrium.

In his treatment of thermodynamics, Nernst made use of Helmholtz's equation relating the diminutions of energy $(U)$ and free energy $(A)$ in a process with the temperature coefficient of the free energy $(d A / d T)$, itself equal to minus the entropy increase $(-\Delta S)$, namely, $A-U=T . d A / d T$. He used this equation with great ingenuity in various fields, and its form lent itself very well to the discovery of the famous Nernst Heat Theorem (sometimes, and by Nernst himself, called the Third Law of Thermodynamics). By an inductive process, based on are extensive knowledge of the experimental results-another characteristic of his procedure-he singled out a field of changes in which the equation $d A / d T=0$ approaches exact validity as the temperature approaches the absolute zero. This implies that $A=U$, and many years previously he had pointed out that this-the so-called Thomsen-Berthelot principle-had a kernel of truth, which could never be disclosed apart from the numerical data. The Nernst Heat Theorem was at first mostly used in the calculation of chemical equilibria from thermal results. In its later developments its intimate relation with the theory of entropy and statistics has been made clear.

It was characteristic of Nernst that he quickly appreciated new discoveries and theories, and that he usually recast the theory into a more intelligible and practical form which appealed directly to chemists. The quantum theory, which was strangely overlooked in England, he recognized as likely to transform many branches of physical chemistry, and in two directions, in photochemistry and the theory of solids, he turned it to most fruitful applications. In the experimental work on the heat capacities of solids at very low temperatures he showed great skill in devising new apparatus-including the use of a metal block as the calorimetric substance-and gave a firm foundation to the quantum theory of specific heats. He invariably strove towards simplification and elimination of redundancy both in theory and in apparatus, and in this work liquid hydrogen was made available in quantity by means of a very simple and effective apparatus at a time when it was regarded as a rarity in most laboratories. He was also interested in the technical applications of physical chemistry, and the Nernst lamp well illustrates his practical ingenuity.

Nernst's work lies at the foundation of many branches of physical chemistry which are most actively studied at the present time, and all physical chemists recognize his outstanding contributions to their science.

J. R. P.

\section{Rev. H. J. Riddelsdell}

HARRY JosEPH RIDDELSDELl entered business after school, but studying in his spare time took the B.A. degree of London and gained an exhibition at Jesus College, Oxford, where he graduated in honours and won the Hall-Houghton Prize. He took Holy Orders, and after holding a curacy at Leeds parish church became sub-warden of St. Michael's College, Llandaff, a post he held for seventeen years. In 1914 he was appointed rector of Wigginton and later became vicar of Bloxham. He retired from parish work in 1936 and died on October 17, 1941.

Riddelsdell's long residence in the country gave opportunity of using his quick eye and active mind in observation of Nature, and enabled him to make a thorough study of the flora of the neighbourhood. In 1907 he published "A Flora of Glamorgan", and from 1901 he contributed numerous notes to the Journal of Botany and other periodicals. He was a frequent contributor to the Botanical Exchange Club and sent valuable notes for the annual reports. The difficult and critical brambles became a special subject under the guidance of the Rev. W. Moyle Rogers, and after the death of the latter Riddelsdell became the leading authority on the genus in Britain and determined specimens for collectors. He visited many parts of Great Britain for the purpose of this study and a number of new forms were described.

The work to which Riddelsdell gave most of his leisure and ripe knowledge was the flora of Gloucestershire, sponsored by the Cotteswold Naturalists' Field Club. From 1908 as editor he organized and directed the work of Club members and dealt with the large quantity of lists and records already accumulated. A final revision had begun when illness compelled him to leave the task unfinished.

Riddelsdell was first and foremost a faithful and scholarly servant of the Church, devout and unselfish and loved by all around him. In addition, his energy, enthusiasm and quick apprehension enabled him to accomplish much in his leisure and made him a delightful companion in the field. He was elected associate of the Linnean Society in 1925 and his valuable herbarium is preserved in the British Museum (Natural History). W. C. BARToN.

We regret to announce the death of Captain Guy Dollman, assistant keeper of zoology (first class) in the British Museum (Natural History), on March 13, aged sixty-five. 